\title{
Noise Waveforms within Seabed Vibrations and Their Associated Evanescent Sound Fields
}

\author{
Richard Hazelwood ${ }^{1, *}$ and Patrick Macey ${ }^{2}$ \\ 1 R \& V Hazelwood Associates LLP, Guildford GU 8UT, UK \\ 2 PACSYS Ltd., Strelley Hall, Nottingham NG8 6PE, UK; patrickm@pafecfe.com \\ * Correspondence: acoudick@gmail.com; Tel.: +44-1483-568646
}

check for updates

Citation: Hazelwood, R.; Macey, P.

Noise Waveforms within Seabed

Vibrations and Their Associated Evanescent Sound Fields. J. Mar. Sci. Eng. 2021, 9, 733. https://doi.org/ $10.3390 /$ jmse 9070733

Academic Editors: Christine Erbe Michel André and Chun-Feng Li

Received: 30 March 2021

Accepted: 15 June 2021

Published: 2 July 2021

Publisher's Note: MDPI stays neutra with regard to jurisdictional claims in published maps and institutional affiliations.

Copyright: (c) 2021 by the authors. Licensee MDPI, Basel, Switzerland. This article is an open access article distributed under the terms and conditions of the Creative Commons Attribution (CC BY) license (https:// creativecommons.org/licenses/by/ $4.0 /)$.

\begin{abstract}
While the effects of sound pressures in water have been studied extensively, very much less work has been done on seabed vibrations. Our previous work used finite element modeling to interpret the results of field trials, studying propagation through graded seabeds as excited by impulsive energy applied to a point. A new simulation has successfully replicated further features of the original observations, and more field work has addressed other questions. We have concentrated on the water-particle motion near the seabed, as this is well known to be critical for benthic species. The evanescent pressure sound fields set up as the impulsive vibration energy passes are expected to be important for the local species, such as crabs and flatfish. By comparison with effects occurring away from boundaries, these seismic interface waves create vigorous water-particle motion but proportionately less sound pressure. This comparative increase ratio exceeds 12 for unconsolidated sediment areas, as typically used for piling operations.
\end{abstract}

Keywords: seismic interface waves; dispersion; water-particle velocity; seabed vibration

\section{Introduction}

\subsection{The Need for More Research into Seabed Vibration}

Sound pressure waves within the marine environment are regularly monitored and regulated to minimize adverse effects on marine life [1-6]. In contrast, few authors have raised concern over the potential effects of seabed vibration. The topic is more complex for many reasons. First, there are a large range of seabed types. Many measurements have been made, and the reviews by E.L. Hamilton [7] have been found useful. This work has concentrated on flat areas of saturated sediments.

Where seabed structures have been considered in acoustic modeling, most consider the seabed to be a fluid, as did Heaney et al. [8]. This reduces the complexity of the calculation, but also misses many of the effects discussed here. There have been other approaches to modeling the seabed structure that will be discussed later. Hawkins et al. [9] have called for a better approach.

The initial work was driven by a desire to understand measurements made at various sites, as well as effects reported in the literature. The relatively simple propagation in the open water environments inhabited by the more charismatic species, such as marine mammals, is here contrasted with highly selective and delayed propagation through the sediment structure. There are some useful analogies with the ducted pathways found in the ocean, such as the mixed-layer water-surface duct described by Urick [10]. If the surface waters are isothermal, the refraction of sound is controlled by a gradual increase of the speed of sound with depth as the pressure rises. This causes energy to be returned to the sea surface following circular pathways, and reduces the geometric attenuation with distance near the surface. However, attempts to use this increase for communication are affected by unpredictable converging paths. 


\subsection{The Issues Addressed in the Paper}

The paper is structured as follows: We discuss the choice of physical models and the care required to obtain valid results with the transient finite element (FE) modeling technique. We then present summary results from the ongoing research with some new conclusions regarding the predicted effects on those creatures inhabiting the benthic region in and on the seabed. We compare results with the mathematics of continuous waves. A separate section will discuss some additional measurements made to study the water motion induced by seismic interface waves in a reservoir.

\section{Using Models to Understand the Observations}

\subsection{Modeling the Physical Environment}

A quantitative study of seabed propagation requires the adoption of a physical model. One proposed by Lord Rayleigh [11] used an infinite interface, such as a horizontal division of all space. Rayleigh assumed a uniform solid under a vacuum. He showed how the waves that travel along this idealized interface show many properties of earthquakes. Such seismic interface waves create coupled horizontal and vertical motions with a characteristic difference in phase. Later, Scholte [12] added a fluid upper half-space with similar results.

A notable flaw in these models is the lack of any dispersion. Observed seismic interface waves are seen as wave packets (see Stein and Wysession [13]), wherein various frequency components travel at different speeds. Typically, a short packet becomes extended in its duration, so that the peak intensity is reduced as the energy is distributed in time.

As pointed out by Shearer [14] and Achenbach [15], dispersion does not occur in either of the half-space models of Rayleigh or Scholte. We used a more realistic half-space model from our earlier work [16] with gradually increasing material stiffness with depth. This is seen to support vibration wave modes that travel at different speeds. However, in this work we also compared these modes with those created by a sharply layered substrate. Results from this layered model contrasted strongly with those of the graded sediment model. A layer of much stiffer material, with its second distinct interface, created a defined depth with a strong effect on the modal structure of the response.

\subsection{The Smoothly Graded Sediment Model}

The graded half-space model is based on the Scholte model [12], but with a steady increase of the solid material stiffness with depth below the seabed, rather than a uniform material. This stiffness can be described by the speed of shear waves, $V_{s}$, as propagated within a uniform material. Material properties can be defined by this and the speed of compressive waves, $V_{p}$, plus the solid density, $\rho_{s}$. Published data was reviewed by Hamilton [7] in this format to provide a range of measured seabed properties. We set a constant solid density of $2250 \mathrm{~kg} / \mathrm{m}^{3}$, which was not found critical. $V_{p}$, the value of the solid compressive wave speed at the interface, was set at $1520 \mathrm{~m} / \mathrm{s}$. The water density was set at $1000 \mathrm{~kg} / \mathrm{m}^{3}$, while the speed of waves in water, $c_{w}$, was set at $1500 \mathrm{~m} / \mathrm{s}$. Again, these are not critical properties.

Unlike the model proposed by Godin and Chapman [17] we specified a step change of material shear speed, $V_{s}$, at the interface, followed by a linear increase with sediment depth, rather than their power-law increase, with its imperceptible initial change at the interface. Our choice of parameters was based on Hamilton's data, mainly lying within the considerable variation he described. The initial fit by Hazelwood and Macey in 2016 [18] was simplified for the 2018 paper [16] to a linear increase of $V_{s}$ with depth $d$. The function $V_{s}(d)$ then has a gradient, $g_{r}$.

$$
V_{s}(d)=V_{s}(0)+g_{r} d
$$

Typical gradients of around $4(\mathrm{~m} / \mathrm{s}) / \mathrm{m}$ were also discussed in Jensen et al. [19]. Specifying this parameter creates an energy duct with some similarities to the surface mixed water duct described by Urick [10]. The linear gradient gives rise to refraction of wave energy back towards the interface, where it combines to form seismic interface waves. These trap the energy as an elastic wave travelling close to the interface. Our studies used 
transient finite element techniques (FE) to show the nature of the coupling of the solid motion with that of the adjacent sea water. Note that we did not specify any absorption, or consider the effects of gravity. We considered the material within each element as isotropic without the internal structure described by the Biot theory [20]. We are only studying wavelengths much bigger than the element size.

We can define the graded physical model with one additional condition, that of Poisson's ratio at great depth. In our model, this tended towards a value of 0.25 , creating a solid similar to granite, a type known as a Poisson solid. This controlled the increase in $V p$ with depth as set out by Hazelwood and Macey 2018 [16]. These few parameters were judged to be reasonably realistic, and their consequences were used to make useful predictions, some of which remain to be tested.

\subsection{The Sharply Layered Model}

The smoothly graded model can be contrasted with a sharply layered model, wherein different adjacent layers have quite different material properties, rather than a gradual change. Such models are much used by seismologists, as the reflected waves yield useful information on the location of minerals, but we are more interested in the seabed interface and its substrate.

We investigated this using the mathematics given by Fahy [21] for a flexural wave excited in a steel plate, which then excites an adjacent fluid volume. This would apply equally to a rock layer, but we have kept the steel layer, with its well-defined material properties, for our computer analysis and comparison of the FE results with continuous wave theory.

\section{The Mathematics of a Continuous Evanescent Pressure Field}

Most available mathematics use continuous waves with no start time that extend throughout all space, but yield convenient mathematical forms such as the sine wave. They can be compared to excitation by an impulse, such as that used for our computer modeling. The mathematical nature of these pressure fields was discussed by Fahy [21]. He showed that when the speed of the solid wave is less than that of the pressure wave in the adjacent fluid, there will be no radiation of energy from the plate into the fluid. The resultant exponential decay of the acoustic pressure with increasing distance from the plate is described as an evanescent field.

The decay can be described by a field thickness $\delta$. While both particle velocities and pressures decay at the same rate, it is convenient to consider the variation of the acoustic pressure, $p$ :

$$
p=p_{0} e^{-\frac{z}{\delta}}
$$

The pressure at the interface $p_{0}$ will have dropped to a fraction $1 / \mathrm{e}$ when the distance from the interface $z$ is equal to $\delta$. This field thickness will vary with the oscillatory frequency and other parameters. This exponential decay is similar to the "skin effect" of electromagnetic theory.

The evanescent field thickness is proportional to the wavelength of the interface wave, $\lambda$ :

$$
\delta=\frac{\lambda}{2 \pi \sqrt{\left(1-\left(\frac{c_{d}}{c_{w}}\right)^{2}\right)}} \approx \frac{\lambda}{2 \pi} \text { when } \frac{c_{d}}{c_{w}} \text { is small }
$$

where $c_{w}$ is the compressive water wave speed and $c_{d}$ is the particle displacement interface wave speed. This equation has been reconfigured to use the wavelength, $\lambda$, from Fahy's original, which used the wavenumber. When $c_{w}>c_{d}, \delta$ becomes close to $\lambda / 2 \pi$, the inverse of the wavenumber, $k$, for the wave being driven along the solid interface, is given by:

$$
k=\frac{2 \pi}{\lambda}=\frac{2 \pi f}{c}
$$


In Equation (3), Fahy's wavenumber ratio has been replaced by a ratio of wave speeds. Since both waves have the same frequency, $f$, their ratio is the inverse of the wavenumber ratio.

\section{Results from Transient Finite Element (FE) Modeling}

\subsection{The FE Graded Model}

Unlike an infinite physical model, the FE mesh is finite. We created a set of elements by defining a data file of their properties for the computation. These small contiguous blocks had specified isotropic material properties, which were then subjected to small elastic deformations by the imposed force. These deformations were transmitted from element to element by a large number of elastic responses between the elements. The FE process is linear, in that if the force is doubled, all responses are also doubled. We thus used an arbitrary $1 \mathrm{MN}$ peak force to generate realistic responses. A benefit of the transient analysis is the ability to use an impulsive excitation force. This has to be kept short in both time and space to avoid unwanted errors, but will track changes with time. We used a more flexible impulsive force for this work than those we used previously.

The FE model was a pair of stacked discs, shown in cross-section in Figure 1. The lower disc was solid, with a depth usually specified as $128 \mathrm{~m}$, of which just over $2 \mathrm{~m}$ is shown, but the disc radius varied, often set to $256 \mathrm{~m}$. Many thousands of elements were defined, with the smaller elements shown by the grid in this figure being $0.125 \mathrm{~m}$ square. These needed to be kept small compared with the wavelength. By doing so, the discrete divisions between the elements had little effect, and the FE model could simulate the continuous variation in material properties of the physical model.

The displacement waves are shown by an exaggerated deformation of the interface. Here, five troughs or dips are shown with a wavelength of approximately 12 elements or $1.5 \mathrm{~m}$. The upper disc is water, with a depth of $16 \mathrm{~m}$, of which the lower $1.7 \mathrm{~m}$ is shown. Note that this model assumed axisymmetry, with no circumferential variation.

Defined points in the FE model are called nodes, corresponding to particles of solid or water. Node 700 is marked on the interface. This is halfway out from the centre at $128 \mathrm{~m}$ radius. Node 920 is within the water at $0.5 \mathrm{~m}$ above the interface. More effort was placed on the analysis of such nodes in this paper than in our previous work. The primary calculation for these acoustic elements is of the acoustic pressure, but postprocessing can be done to recover the water-particle motion.

\subsection{The FE Layered Model}

The layered physical model is more easily rendered by the FE technique, as the substrate layer is finite. Steel was used, with its well-defined material properties, but the mathematics will be similar for a rock layer.

The diameter was made large enough to be able to avoid confusion between the outgoing wave and the return after a reflection at the circumference. This FE model will be referred to as the tank model, representing a $16 \mathrm{~m}$ deep water tank of diameter $512 \mathrm{~m}$ with a $0.125 \mathrm{~m}$ thick steel base. Excitation forces were applied downward to the tank centre, using low frequencies (e.g.,16 Hz) to create an evanescent pressure field in the water near the bottom.

Although the motion of the steel plate was primarily vertical, the adjacent water motions retained the substantial horizontal velocities of the graded model. This indicated that these water-particle velocities were a consequence of the intrinsic fluid mechanics within the evanescent field, and were independent of the horizontal motion of the solid below. The fluid as modeled had no viscosity. 


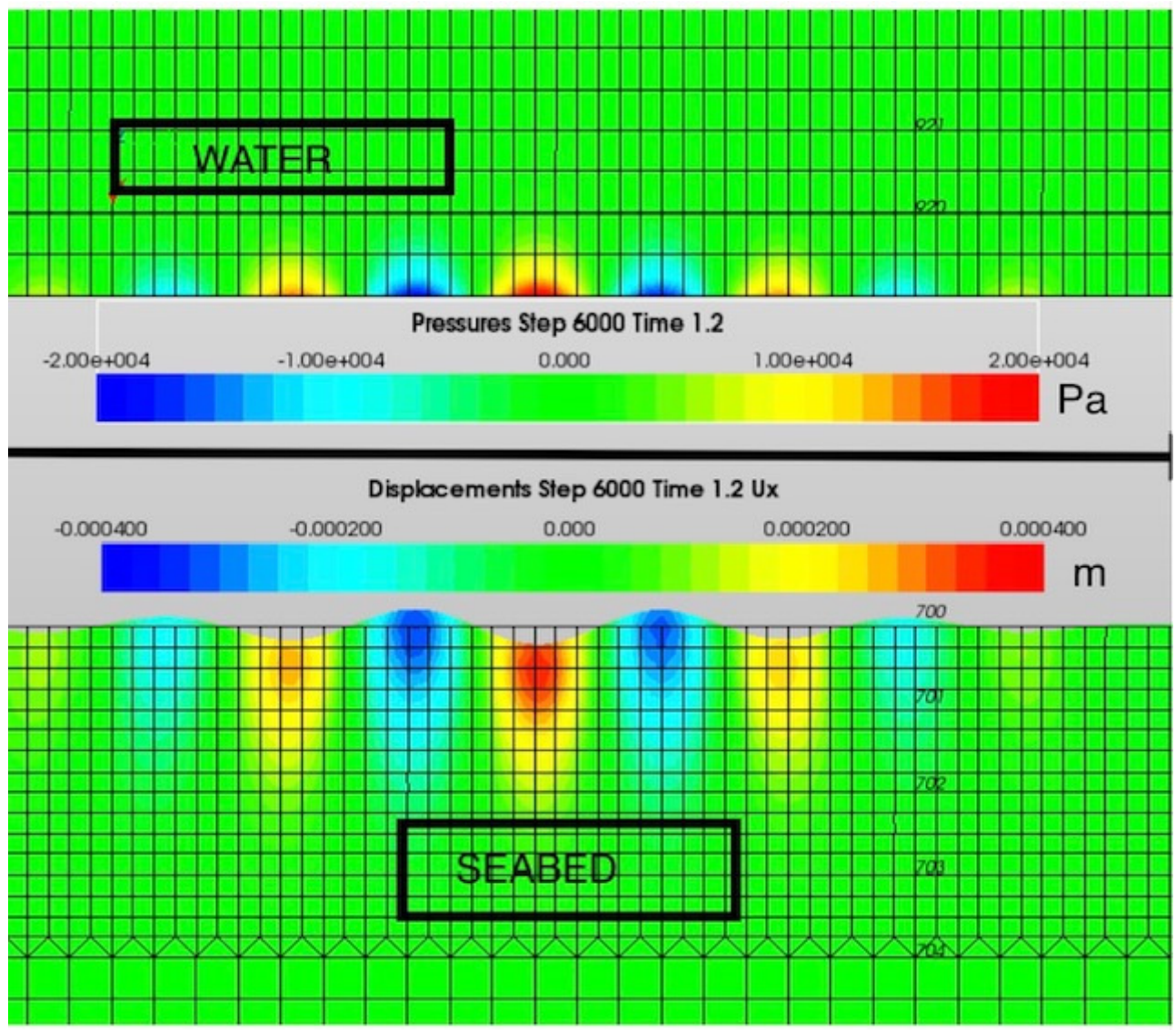

Figure 1. An enlarged view of a section through the FE model shows two parts. The upper section has been processed as a fluid (water) to give a distribution of acoustic pressures. The lower section has been processed to show the deformation of the solid. A colour barcode shows the range of the vertical displacements, from $+0.4 \mathrm{~mm}$ to $-0.4 \mathrm{~mm}$. The upper section was connected by computation to the lower section to create the acoustic pressure range $\pm 20 \mathrm{kPa}$. This snapshot view was at a time of $1.2 \mathrm{~s}$, after 6000 computational time steps had been completed.

\subsection{The Nature and Influence of the Energy Source}

Both the graded and layered FE models were excited by a force applied as a downward thrust at the centre of the substrate disc. This was chosen to represent the actions of a pile driver or dredger. However, there was limited realism in this choice. The FE method had difficulty in modeling a cutting action. Both piling and dredging require the rupture of the seabed material, and this was outside the scope of this work. However, the elastic waves as modeled showed most features of the observed seabed vibrations, so we studied the propagation from the idealized thrust to the consequent motion.

The displacements of the particles as shown in Figure 1 created two particle velocity components, described henceforth as upward and outward. In contrast, the applied thrust was only vertical, and applied to a point at the centre of the model. The horizontal velocities that were integral to the seismic interface wave structure were thus generated within the model, as the energy was converted from that of a vertical thrust into a two-dimensional velocity vector. There was no circumferential velocity in this axisymmetric model. This conversion process may have some similarity to the process that converts a fluctuating volume source (a "simple source" as described by Kinsler et al. [22]) into a plane pressure wave within open water. This is usually described by comparing the simple physics of the near field to that of the far field, with a more complicated structure as the conversion proceeds. 


\subsection{The Energy-Source Time Profile}

Our 2016 work used a polynomial variation of thrust with time over a defined period, designed to limit the acceleration values. For the 2018 work, this was changed to a Ricker pulse, an infinite pulse profile, with very low values at times well away from the peak. The profile was truncated at a time when the level was extremely low.

Both these pulse forms have been replaced in this work by a truncated windowed cosine form. The cosine form was windowed by a Gaussian "bell" curve, as seen in Figure 2. In addition to the cosine frequency $\mathrm{f}$, set here to $40 \mathrm{~Hz}$, the bell curve was specified by a time width, $t_{w}$, and a peak time, $t_{0}$. The peak amplitude force $F$ was set at an arbitrary $K=1 \mathrm{MN}$. Here, the window width $t_{w}=0.0226 \mathrm{~s}$.

$$
F=K e^{-\left(\frac{t-t_{0}}{t_{w}}\right)^{2}} \cos 2 \pi f
$$

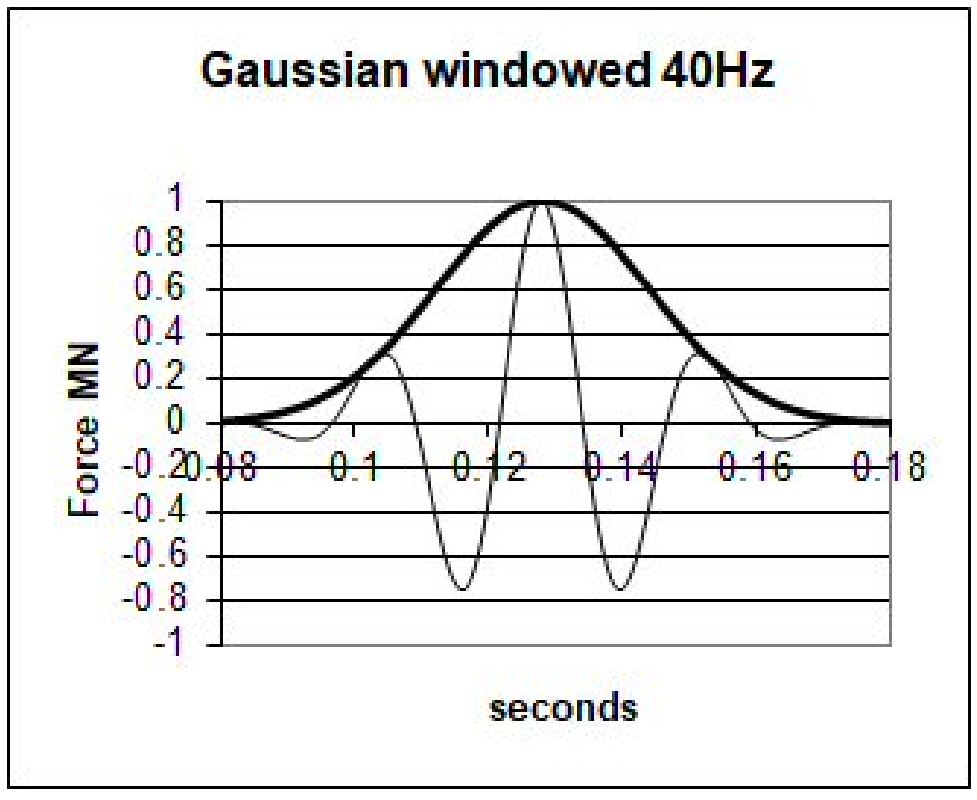

Figure 2. An example of a time profile used in recent FE work.

The envelope form is shown in Figure 2 by the bold black line, while the applied force is shown by the lighter grey line. This improved impulse driver allowed the frequency of the propagated displacement wave to be set. However, it was not based on any measurements of piling action, but rather adopted to replicate features of the observed waveforms.

\subsection{The Time Profile of the Response}

The form of the time response is shown in Figure 3 at two positions, $64 \mathrm{~m}$ and $128 \mathrm{~m}$ from the centre of the model. The response at a radius of $128 \mathrm{~m}$ was taken at node 920 , which is labeled in Figure 1. The water-particle kinetic energy depended on the particle speed, a scalar found by combining the upward and outward velocity components.

Notably, it was the time profile of the particle speed that followed the form of the applied impulse window function, the envelope shape of the wave packet. This bell shape was seen to propagate unchanged from the node at radius $64 \mathrm{~m}$ to that at $128 \mathrm{~m}$. In contrast, the individual velocity components of the displacement wave followed the more rapid oscillations of the applied force. At different positions, the peaks and troughs of the two components occurred at different times within the envelope. This was a consequence of the displacement wave speed being faster than the speed of the envelope. This behaviour is well documented for other branches of physics, in which they are referred to as the "phase velocity" and "group velocity", respectively. These include ocean surface waves, controlled 
by gravity, where the wave structure is highly dispersive, with a characteristic ensuing chaotic motion.
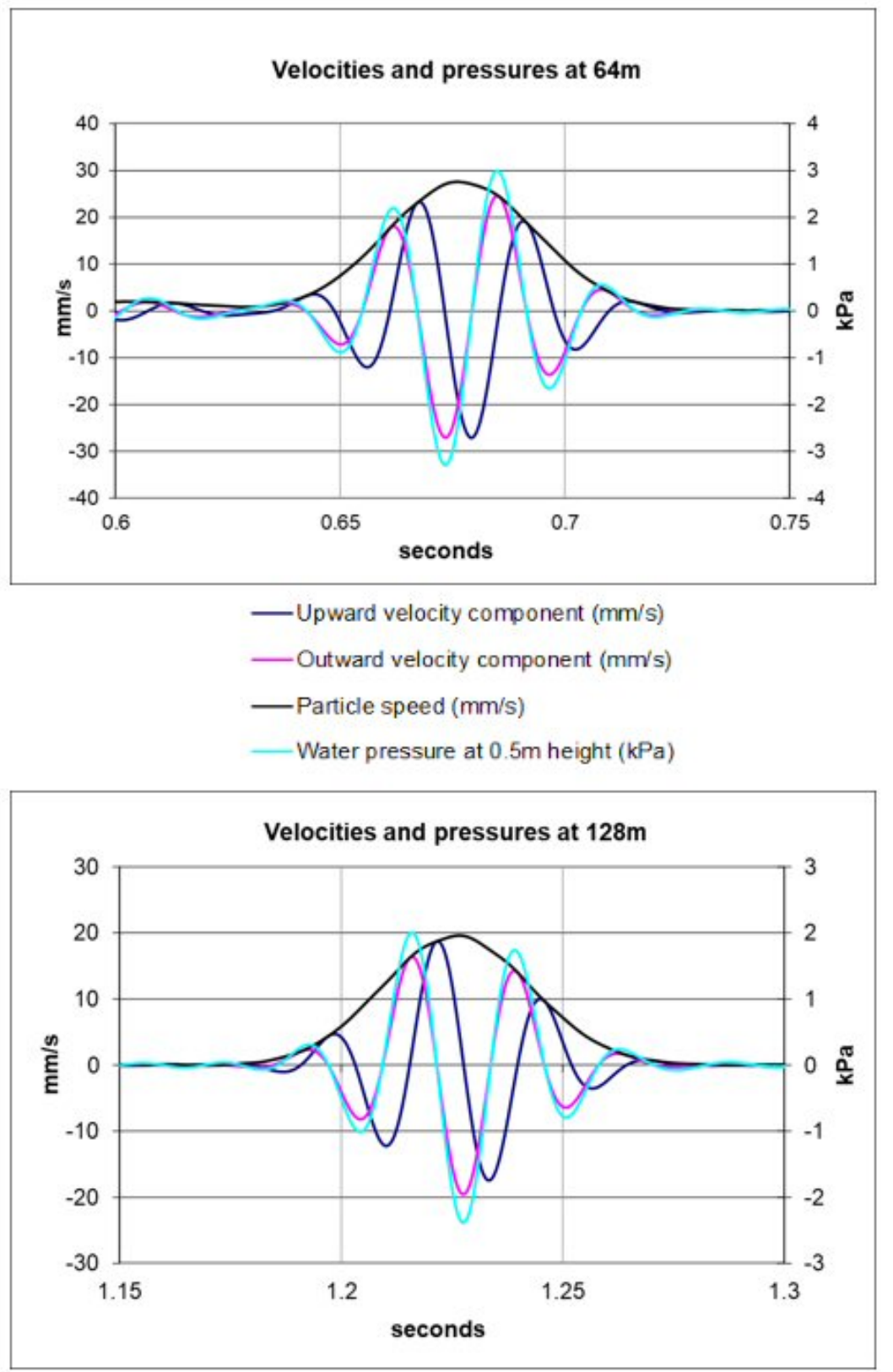

Figure 3. The response of the FE graded model to a Gaussian windowed cosine impulse is shown at two positions, each plotted against time. The two velocity components (upward (dark blue) and outward (mauve)) are combined to show the vector magnitude, the particle speed (black). The pressures (light blue) at this height ( $0.5 \mathrm{~m}$ above the seabed) matched the shape of the outward velocity component.

\subsection{Dispersive and Nondispersive Groups: A Comparison with a Dispersive Substrate}

Dispersive mechanisms are best displayed using animations, and good examples are available online from ISVR [23], and also on Wikipedia as "phase velocity". As shown in Figure 4, these wave packets can propagate without dispersion, but with the packet continuously changing in form as the peaks apparently move through the envelope. The stability of the bell shape was tracked in our models for more than a $500 \mathrm{~m}$ range, showing that there was no dispersion within the packet. 

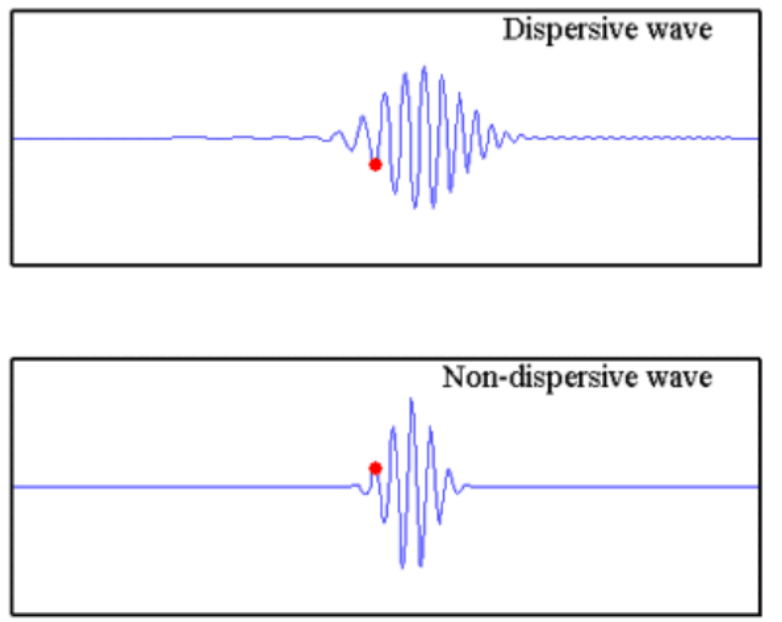

isvr

Figure 4. The difference between a dispersive wave packet and a nondispersive wave packet. The latter shows a uniform frequency content, and remains compact as it travels.

The observed structure of the groups or modes generated within the graded sediment substrate could be compared with a dispersive substrate, that of a steel tank base. Transverse (here, "upward") vibrations within such plates will radiate sound into an adjacent fluid space if the wavelength within the plate is larger than the corresponding wavelength within the fluid. However, if the wave speed within the vibrating solid is less than that of the compression waves within the fluid, an evanescent pressure field is set up in the fluid near the interface.

The steel baseplate of the tank model was made $0.125 \mathrm{~m}$ thick to give a suitably slow speed for $16 \mathrm{~Hz}$ flexural waves, a frequency commensurate with results for the graded seabed model. The solid motion was predominantly vertical, but the water particle response shown in Figure 5 had both horizontal and vertical motion.

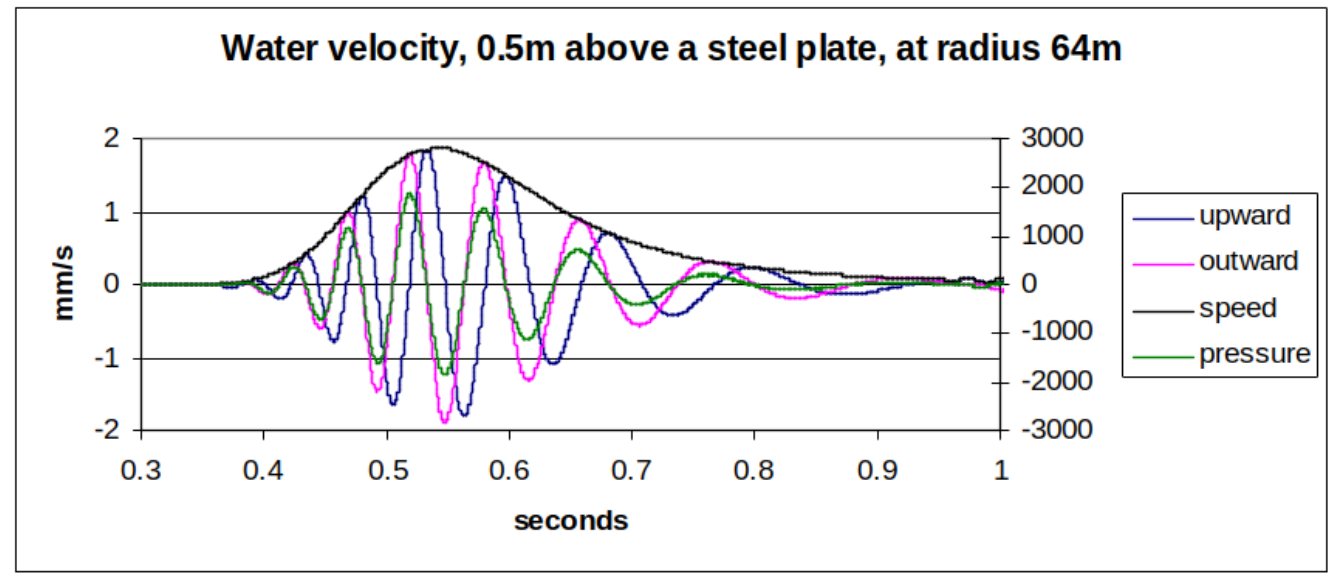

Figure 5. A water-particle response in a dispersive-tank model. The envelope is no longer symmetrical with time, being stretched on its trailing edge by dispersion in the flexural waves of the tank baseplate.

The underlying dispersion is described by the mathematics of the flexural (bending) waves being driven in the baseplate, as given by Fahy [21]:

$$
c_{b}^{2}=2 \pi f \sqrt{\frac{D}{m}}
$$


The propagation speed, $c_{b}$, for these bending waves is dependent on the frequency, $f$, as well as the material properties, including the mass per unit area, $m$. The bending stiffness $D$ is given by the Young's modulus, $E$; the Poisson ratio, $v$; as well as the plate thickness, $h$. (Timoshenko et al.) [24].

$$
D=\frac{E h^{3}}{12\left(1-v^{2}\right)}
$$

The dispersive character could be clearly seen in snapshot views of the impulsive wave train as it propagates.

At $0.35 \mathrm{~s}$, the wave train was well established, seen in Figure 6 as a snapshot including node 600 at radius $64 \mathrm{~m}$. The acoustic pressures in the water were well correlated with the deformation of the adjacent steel plate.

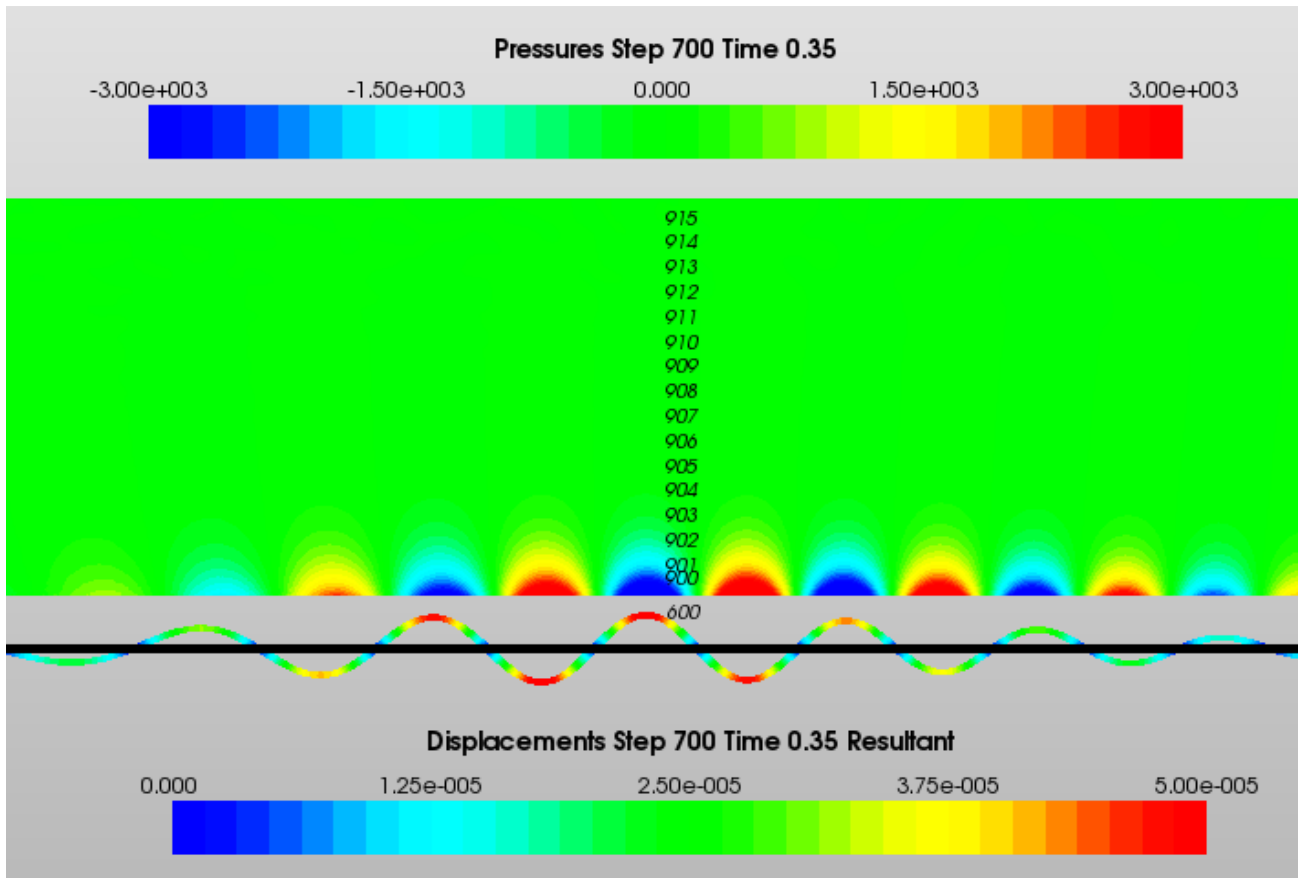

Figure 6. A snapshot view of the flexural wave as an exaggerated displacement of the baseplate. This is shown as a horizontal black line between its exaggerated displacements, in colour, peaking at $50 \mu \mathrm{m}$. The water finite element edges are not shown here, but a set of monitor nodes are numbered in the water column up to the water surface (16 $\mathrm{m}$ deep). The oscillating pressures covered a range $\pm 3 \mathrm{kPa}$.

In Figure 7, at $0.8 \mathrm{~s}$ the pulse has moved out from node 600 to include node 800 at a $192 \mathrm{~m}$ radius. The strong dispersion dramatically increased the length of the wave train. This view had a reduced magnification, with the extended wave train almost extended to the edge of the FE model at a 256 m radius. Note the lack of significant reverberation at this time.

\subsection{A Comparison of Different Modes in the Graded Model}

The bell envelope shown in Figure 3 occurred again (Figure 8), showing two separate bell-shaped modal envelopes in water. The variation with time of the water particle velocity components were plotted, as was the vector magnitude, the particle speed. 


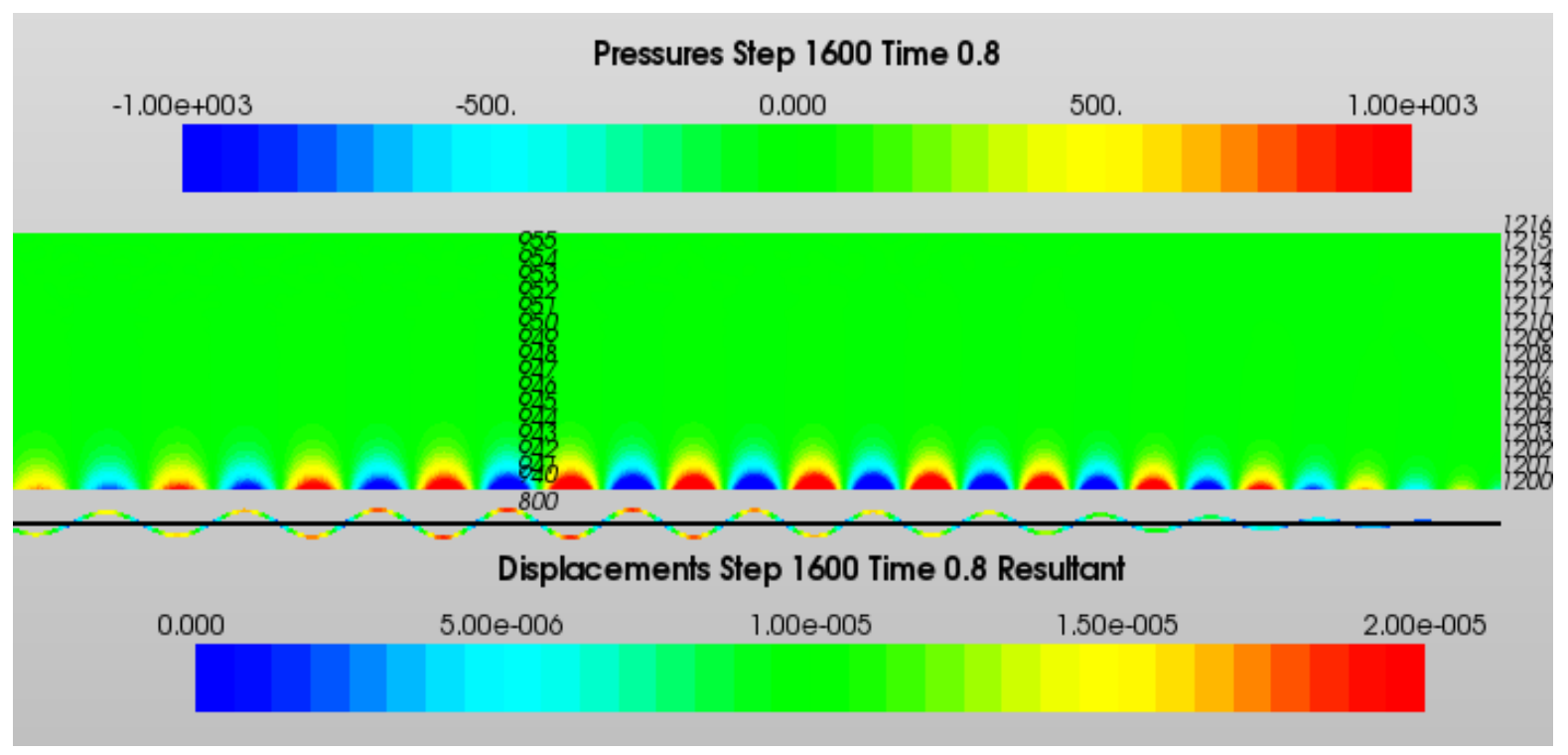

Figure 7. A second snapshot at $0.8 \mathrm{~s}$ also shows the numbered nodes at the edge of the model at a $256 \mathrm{~m}$ radius.
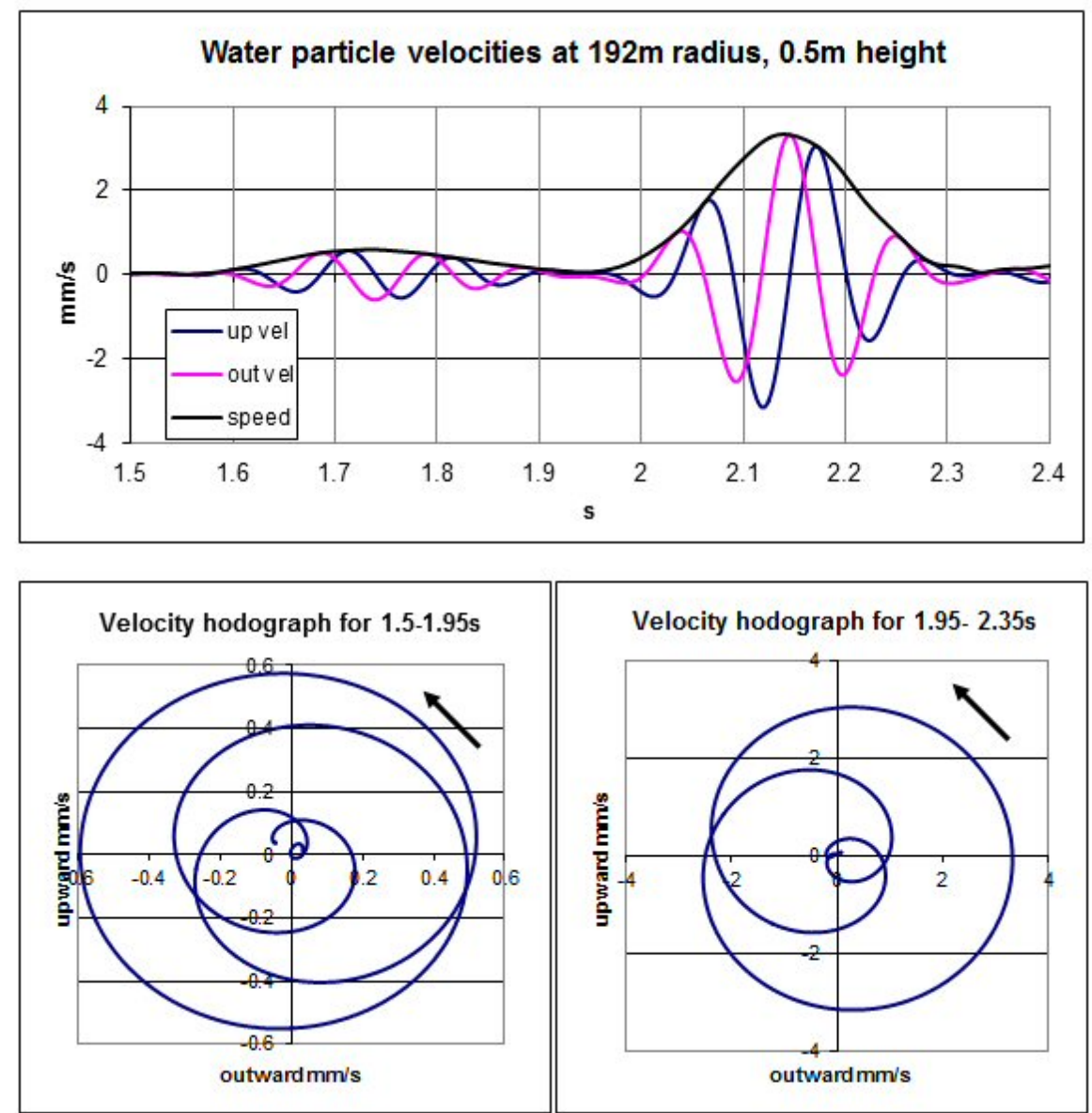

Figure 8. A time series from $1.5 \mathrm{~s}$ to $2.4 \mathrm{~s}$ shows an early mode that is less intense.

The early mode data in Figure 8 was selected ( $1.5 \mathrm{~s}$ to $1.95 \mathrm{~s}$ ) and plotted as a hodograph below the time series. This shows the locus of the motion of the water particle as the early mode passed. A second hodograph shows the data for the period 1.95 to $2.35 \mathrm{~s}$, after a brief moment of inactivity. 
This hodograph data display was so named by W.R. Hamilton [25], and provided additional insight into the motion. Unlike the solid motion, the water particles followed a nearly circular path. As more cycles were included within the envelope, more circuits were observed. For a continuous wave, a single circle would be followed repeatedly, but for an impulse, the motion had to start and stop at the origin.

The arrows show the direction of circulation, which is described as retrograde, with the horizontal velocity being at a maximum in the direction of the source at the moment the upward displacement was at a maximum.

In Figure 9, the motion of a solid particle at the interface is shown. Now the hodographs are highly contrasting both in shape and direction. The less-intense early mode travelled faster $(\sim 140 \mathrm{~m} / \mathrm{s})$ than the more intense mode, which was slower $(\sim 117 \mathrm{~m} / \mathrm{s})$.
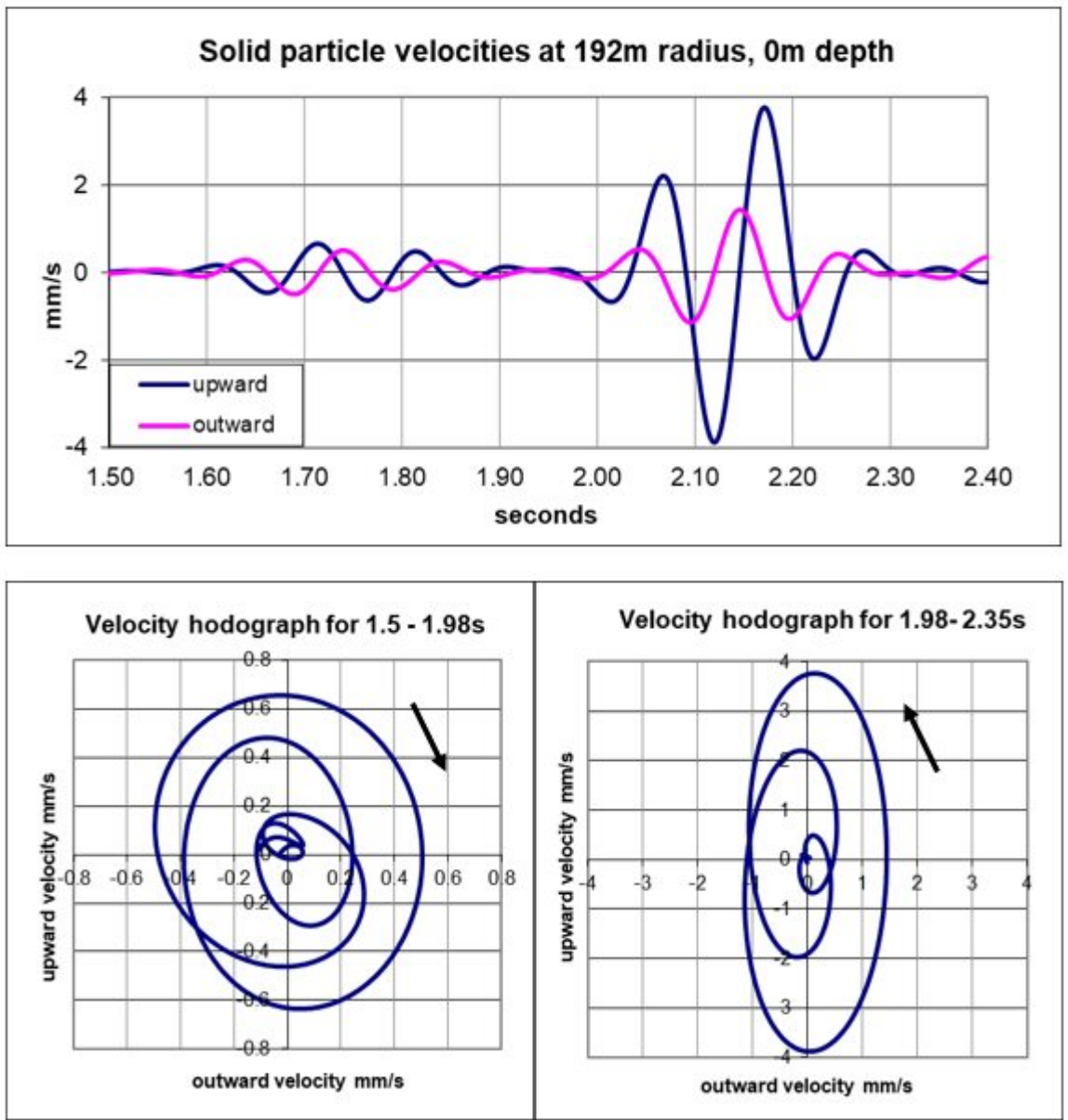

Figure 9. The time series for a solid particle at the interface is shown for the same period of 1.5-2.4 s. Two periods were selected for the hodographs shown below, which differ in both shape and circulation direction.

The more intense retrograde mode is that which we previously studied, but we intended to further investigate the prograde mode, which cannot exist in the Rayleigh half-space model, but propagates stably in the graded half-space.

In Figure 10, both hodographs are prograde, but with contrasting shapes. These examples show how the graded model dispersed energy between modes, but we found no evidence of dispersion within individual modes. In 2018, we showed this by tracking their peak intensities against travel time. There was a good fit for the cylindrical spreading of peak energy, as the wave circumference increased without dispersion. 

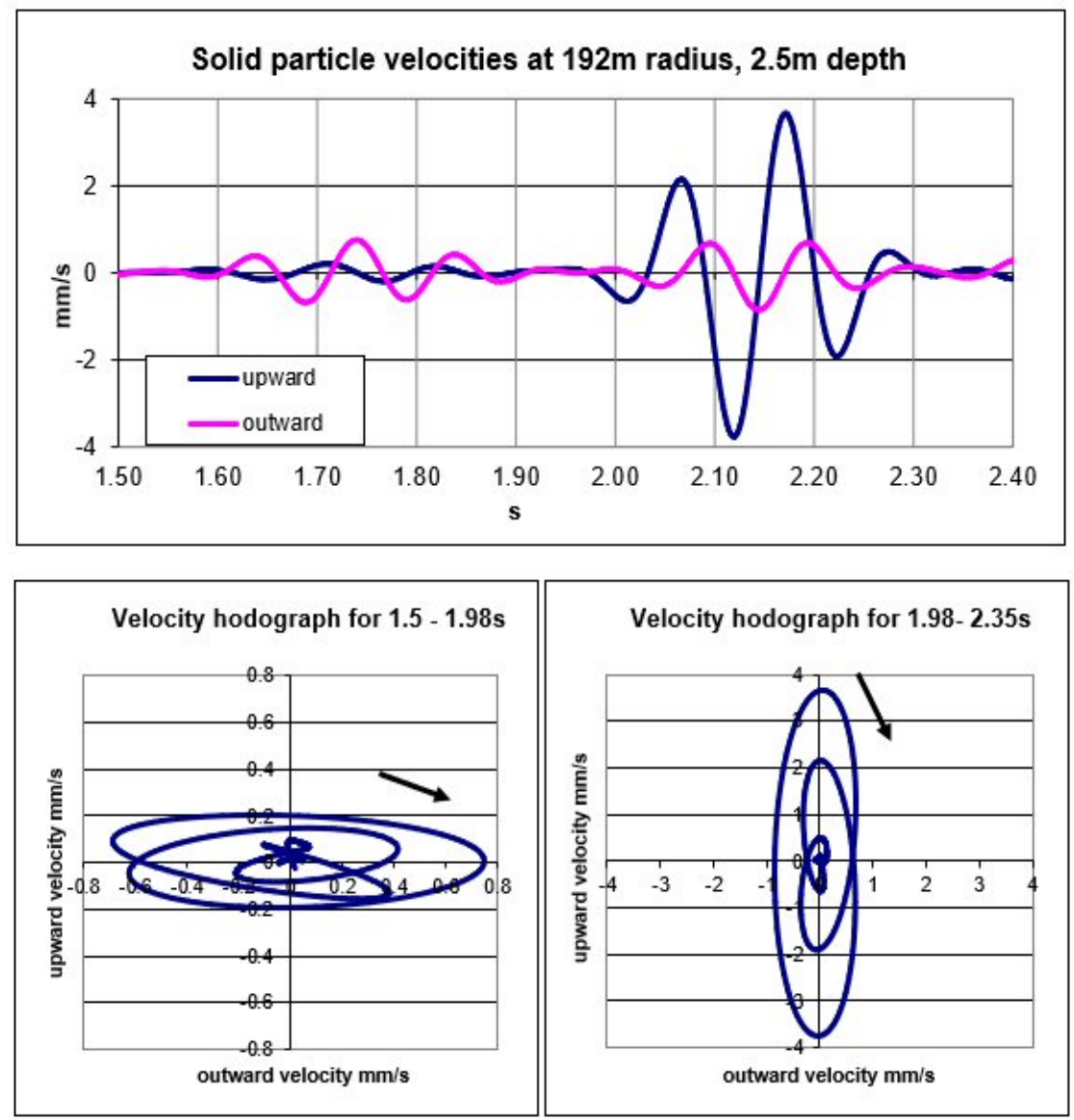

Figure 10. At greater depths, such as $2.5 \mathrm{~m}$ below the interface, both modes became prograde.

For the later mode, a change in direction of the solid motion occurred at a critical depth $(\sim 1.1 \mathrm{~m})$ below the interface. Here, there was no horizontal motion. This phenomenon was described by Rayleigh for the interface waves in a solid half-space, and this similarity showed how the later mode in the graded seabed model was a version of the "Rayleigh wave". The existence of prograde waves at depth was thus expected, but the Rayleigh theory only predicted retrograde motions at the surface with no dispersion.

In contrast, the energy in the graded model was dispersed into at least two modes that travelled at different speeds, and thus reduced the intensity to be found at a distance, but this dispersion was still much less than that to be expected over a layered seabed.

\subsection{The Contrasting Group and Phase Velocities}

Time profiles at two positions were used to measure the travel speed. The Gaussian envelope bell form helped by allowing a precise fit to the data extracted from the FE analysis. This speed was found to be $117 \mathrm{~m} / \mathrm{s}$ when the material shear speed, $\mathrm{V}_{\mathrm{s}}(0)$, at the interface was specified as $128 \mathrm{~m} / \mathrm{s}$. This ratio of $91.4 \%$ can be compared with the interface wave speed for the Rayleigh model given by Achenbach [15] as varying from $86.7 \%$ to $95.5 \%$ dependent on the Poisson ratio of the uniform solid in the half-space. We estimated the precision of our measurement at $\pm 0.5 \mathrm{~m} / \mathrm{s}$, but recognize the uncertainty of the FE procedure, which depends on the accuracy of many successive calculations.

A mathematical analysis of the impulse clearly would be better, if one could be found to give a closed-form solution. However, a discussion with Godin (private communication) suggested that his published method [17] for a power-law depth profile cannot cope with the step change at the interface of our model. 


\subsection{The Influence of the Depth Profile Gradient on the Speed of the Displacement Wave}

The gradient of the material shear wave speed with depth has been found to influence the speed of the displacement wave, $c_{d}$. We know that the greater this depth profile gradient, the more rapidly the wave energies are refracted back to the interface.

Figure 11 shows a snapshot view that was used to measure the wavelength. With a specified frequency of $80 \mathrm{~Hz}$, this determined the displacement (or "phase") wave speed. The smallest elements in this fine-mesh density model were only $0.0625 \mathrm{~m}$ wide.
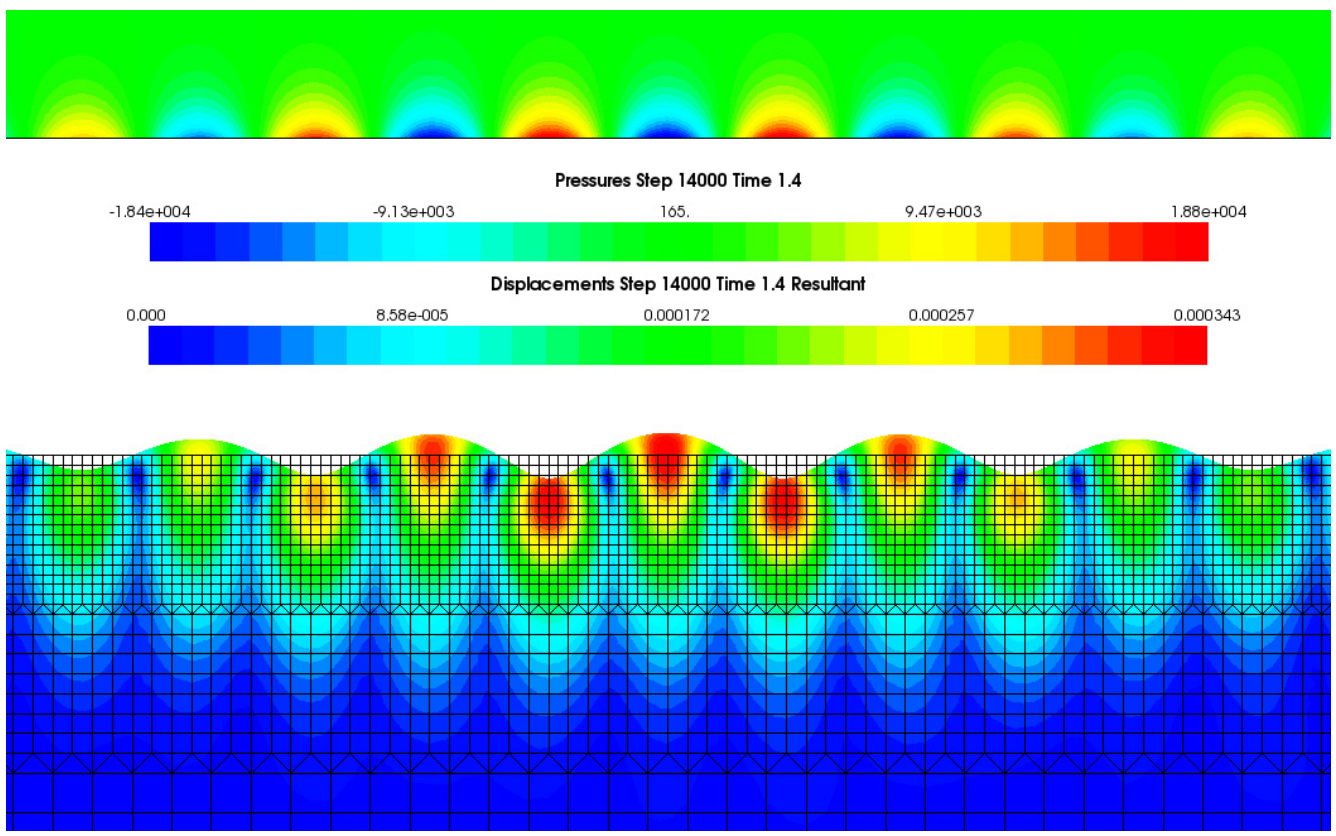

Figure 11. By increasing the mesh density and frequency, the wavelength can be better measured.

Five whole waves were selected, and the corresponding number of elements was found to be 119 . This gave a wavelength of $1.4875 \mathrm{~m}$ and a wave speed of $119 \mathrm{~m} / \mathrm{s}$. The gradient in this model was $4(\mathrm{~m} / \mathrm{s}) / \mathrm{m}$. FE models in a sequence were run, each with different values of the gradient. The results are shown in Table 1 . They were of limited precision, estimated at $\pm 0.5 \mathrm{~m} / \mathrm{s}$, but showed a clear trend.

Table 1. The variation of wave speed with depth profile.

\begin{tabular}{cccccc}
\hline Shear Speed Profile Gradient, $\mathrm{g}_{\mathbf{r}},(\mathbf{m} / \mathbf{s}) / \mathbf{m}$ & $\mathbf{2}$ & $\mathbf{4}$ & $\mathbf{6}$ & $\mathbf{8}$ & $\mathbf{1 0}$ \\
\hline Displacement wave speed, $\mathrm{c}_{\mathrm{d}}, \mathrm{m} / \mathrm{s}$ & 118 & 119 & 120 & 120.7 & 121.7 \\
\hline
\end{tabular}

Improved methods for using the FE methodology to determine $\mathrm{c}_{\mathrm{d}}$ are being considered, including better postprocessing. The precision was increased by using a finer mesh density, but at the expense of much longer run times and large data files.

Making these changes also helped to show that the results were not an artifact of the modeling process. Other checks on the validity of the FE process include changing the boundary conditions of the FE model. A change from a rigid boundary (no motion) to a soft boundary (no forces) would change the phase of any reflected waves, so that the extent of any such reverberation can be monitored and shown not to affect the conclusions.

\subsection{The Evanescent Form of the Associated Pressure Fields in the FE Modelling}

Figure 1 shows the distribution of acoustic pressures within the water as the wave passed. A rapid reduction in amplitude is shown by the green coloration well away from the interface. This distribution was typical of an evanescent field. No energy was radiated away from the interface, with the stored energy being supplied by the travelling seismic 
interface wave, and recovered for onward transmission, assuming there were no losses. In practice, there will be absorption, as the acoustic energy is converted to heat, but that will depend on the local circumstances, and was not modeled here.

Figure 12 shows the acoustic water pressures as a function of the height above the interface. Notably, the waveforms of these time profiles were all in alignment, with peaks occurring simultaneously.

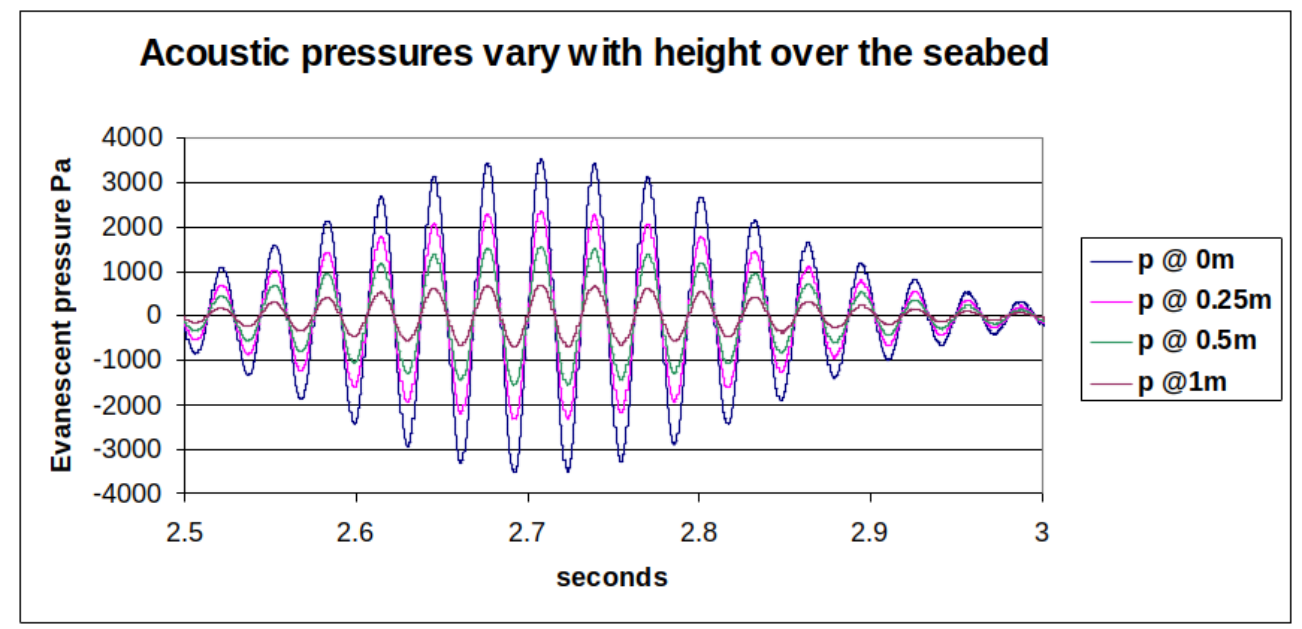

Figure 12. The pressures created at a distance of $256 \mathrm{~m}$ from the source are shown at different heights above the seabed. They oscillated simultaneously, independent of height.

The good fit to the straight line of the continuous wave theory in Figure 13 shows that the evanescent water field followed an exponential decay within this FE model. The field thickness was $0.6 \mathrm{~m}$ for the fitted line, shown for a frequency of $32 \mathrm{~Hz}$. The deviations at greater heights were due to reverberation in the model, but were small compared with the pressure levels at the interface.

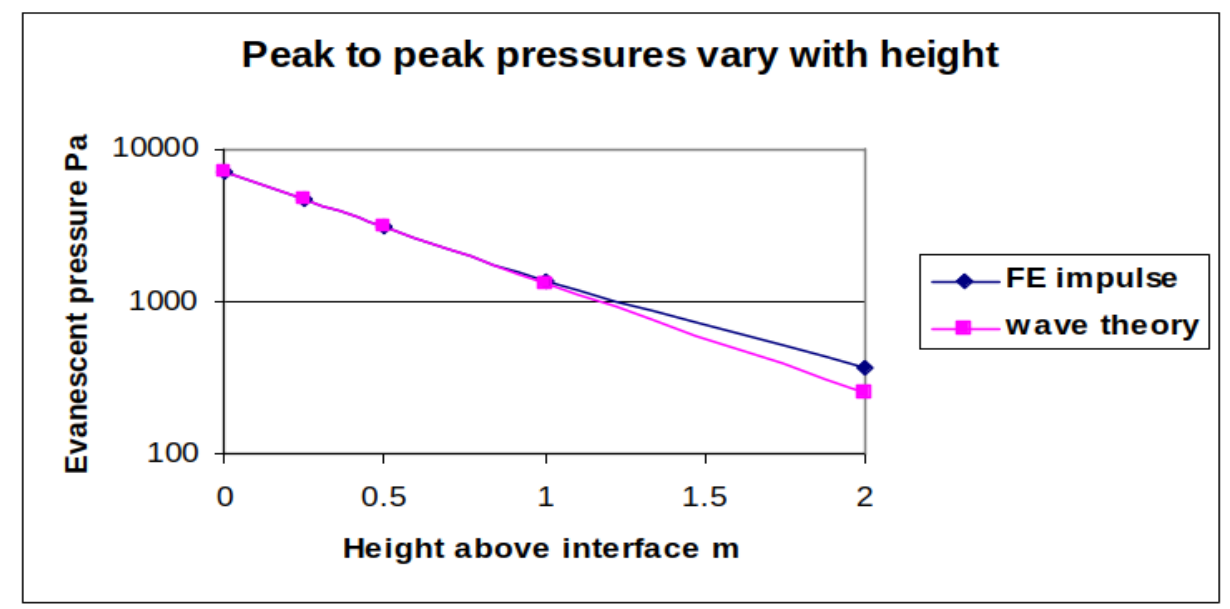

Figure 13. The pressure amplitudes (peak to peak) plotted on a log scale against height.

The displacements below the interface were also shown to be evanescent, with an eventual exponential decay occurring at depths $>10 \mathrm{~m}$, but these fields were more complicated than those in the water above. Different modes travelled at different speeds, with changes in the direction of the motion at defined depths, as can be seen in contrasting Figures 9 and 10. However, the simpler evanescent water pressure field was independent of the horizontal motion of the solid. 


\subsection{Linking the Acoustic Pressure and the Horizontal Water-Particle Velocity}

For continuous plane waves in open water, well away from boundaries, the ratio of acoustic pressure to the water particle speed is called the specific acoustic impedance (Kinsler et al. [22]). This is a scalar, dependent on the water density, $\rho_{\mathrm{w}}$. Only compression waves are propagated in a fluid, and the particle motion lies along the direction of energy propagation, so that the speed is just this velocity component. However, in an evanescent field, the water particles move with velocities that have components in multiple directions.

It is then appropriate to use the inverse of the impedance, the admittance, as a complex vector, which is the water-particle velocity vector, $u$, divided by the scalar pressure, $p$. The complex vertical admittance component is imaginary, the pressure waveform is out of phase with the vertical velocity, and there is then no work done on the fluid by the motion of the solid (Fahy [21]). We denoted the vertical velocity component as $u_{v}$ and the horizontal component as $u_{h}$.

Then, the vertical admittance becomes:

$$
\frac{u_{v}}{p}=\frac{j}{\rho_{w} c_{d}} \sqrt{\left(1-\left(\frac{c_{d}}{c_{w}}\right)^{2}\right)}
$$

The horizontal admittance is a real quantity and derived in the same way as that for continuous plane waves (Kinsler et al. [22]), but is dependent on the displacement wave speed, $c_{d}$.

$$
\frac{u_{h}}{p}=\frac{1}{\rho_{w} c_{d}}
$$

The square root term in Equations (3) and (8) can now be considered as a "shape factor", since it will control the shape of the water-particle hodographs. When $c_{w}>c_{d}$, this factor is close to unity, and the hodograph is circular, but as the ratio decreases, the hodograph becomes elliptical with comparatively reduced vertical motion.

\subsection{A Comparison of Water-Particle Motions in the Evanescent Field to Those in Plane Waves}

With the knowledge that it is the water-particle motion that is sensed by many subsea creatures, it is common to infer this parameter from a measured acoustic pressure, using the specific acoustic impedance, $\rho_{w} c_{w}$. However, this inference is invalid when the acoustic pressure is created by a seismic interface wave and the displacement wave speed, $c_{d}$, should be used in place of $c_{w}$.

It is convenient to use a unitless velocity-to-pressure ratio (VPR). This is done by comparing the evanescent field horizontal admittance to the value for acoustic plane waves in open water. From the data shown in Figure 3, we found a VPR just over 12.0 for the windowed wave packet used.

In contrast, if we used Equation (9) for a continuous wave, with the value for $c_{d}$ of $119 \mathrm{~m} / \mathrm{s}$ for a value of $\mathrm{gr}=4$ (Table 1 ) and a value of $c_{w}=1500 \mathrm{~m} / \mathrm{s}$, we calculated a VPR of 12.6. More work is planned to investigate how this difference was influenced by other factors, such as the properties of different finite-length wave packets. However, it was clear that the VPR was substantial in all realistic cases, and a value of 12 provided a fair working estimate. This showed how much more significant the water-particle motions were in comparison to the acoustic pressures in the evanescent field.

It is also interesting to measure this ratio in practice by comparing the values from a hydrophone with a water-particle velocity sensor.

\section{Additional Field Trials}

\subsection{Methods}

The prediction of the strong linkage between the local evanescent pressures and the horizontal water particle velocity led to a trial in the still waters of Wraysbury reservoir, where a test facility is operated by the National Physical Laboratory (NPL) Teddington, London. 
Figure 14 shows the stainless-steel sledge fitted with various instruments on cables to allow their deployment onto the clay bed $20 \mathrm{~m}$ below the raft. The central housing contained a set of three orthogonally mounted geophones. This is the same instrument that was deployed into the Rhine estuary at Kinderdijk and reported by Hazelwood and Macey 2016 [18]. As before, the deployment used an extra line attached to the sledge prow (Figure 14) to tow the sledge a short distance, thus aligning it with respect to the raft.

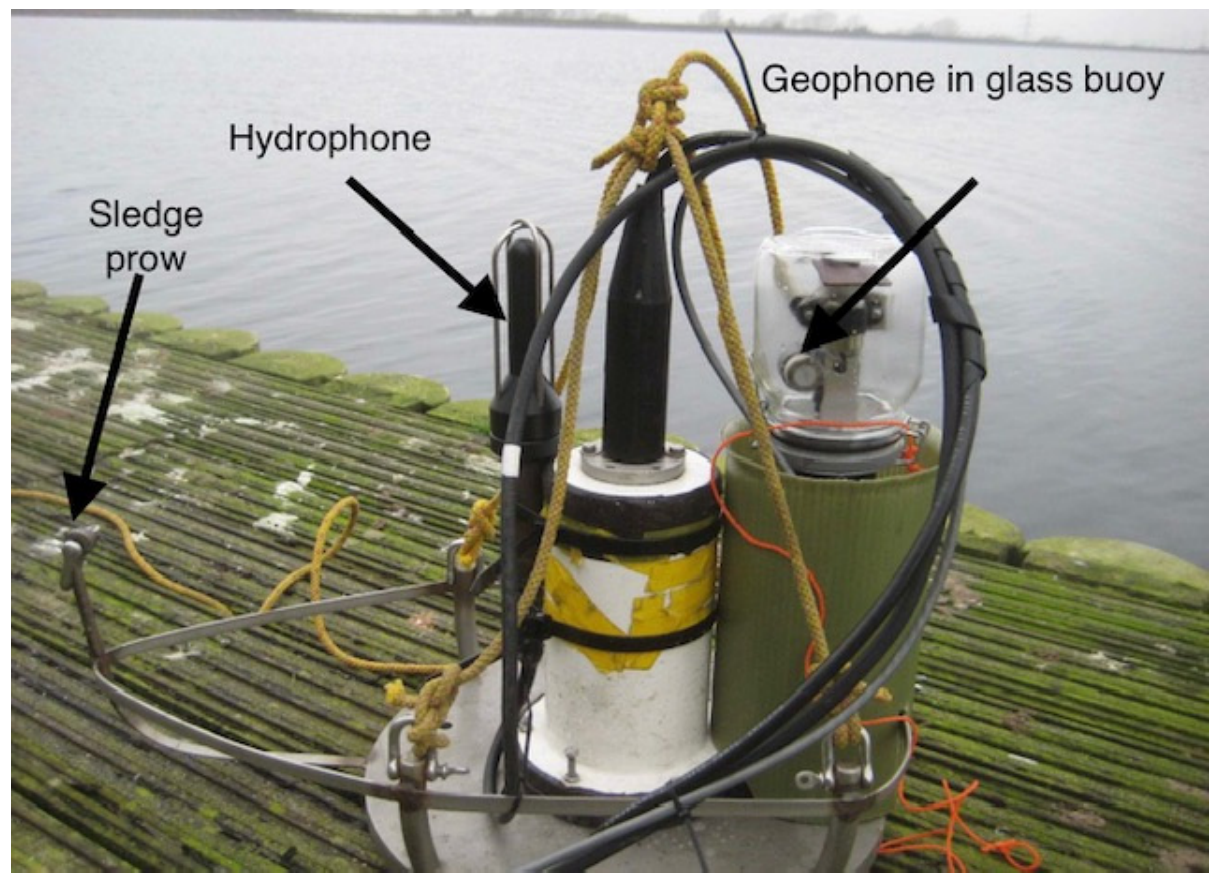

Figure 14. The test rig ready for deployment at Wraysbury in March 2017.

Two additional instruments were added, each with their own cables. A hydrophone was supplied by NPL, and an experimental glass buoy was held in a holster, which allowed it to float clear once deployed into the water. This was then held down by a light coiled spring, which had been previously tested to give a vertical resonance with a low natural frequency $<5 \mathrm{~Hz}$.

One of the set of geophones in the buoy can be seen through the glass. The use of more geophones allowed the same low-noise, low-impedance preamplifiers to be used as developed for the Kinderdijk trial. These geophones were well adapted to sense velocity over the frequency range 10-200 Hz, with a flat sensitivity of $20 \mathrm{~V} /(\mathrm{m} / \mathrm{s})$. It was thus useful to compare their outputs with that of the hydrophone, which had a pressure sensitivity that was flat over the same frequency range.

The seismic interface wave was generated by the impact of a $20 \mathrm{~kg}$ bronze cylinder with the bed of the reservoir, after being dropped from the raft. The cylinder was streamlined with a cylindrical rear fin to maintain its attitude during the descent, and recovered by winch using a rope, flaked out on the raft deck before the drop to minimize drag. Several drops were made with similar results.

\subsection{Results}

The principal finding shown in Figure 15 was that the shape and phase of the hydrophone time series (dark blue) largely matched that of the horizontal y velocity component (green) given by one of the geophones. The data shown was used to estimate the VPR. The peak-to-peak (p-p) amplitude of the y component data was $43.6 \mu \mathrm{m} / \mathrm{s}$. The amplitude of hydrophone data was $16.5 \mathrm{~Pa}$. The ratio of pressure to velocity was $378 \mathrm{~Pa} /(\mathrm{mm} / \mathrm{s})$. 


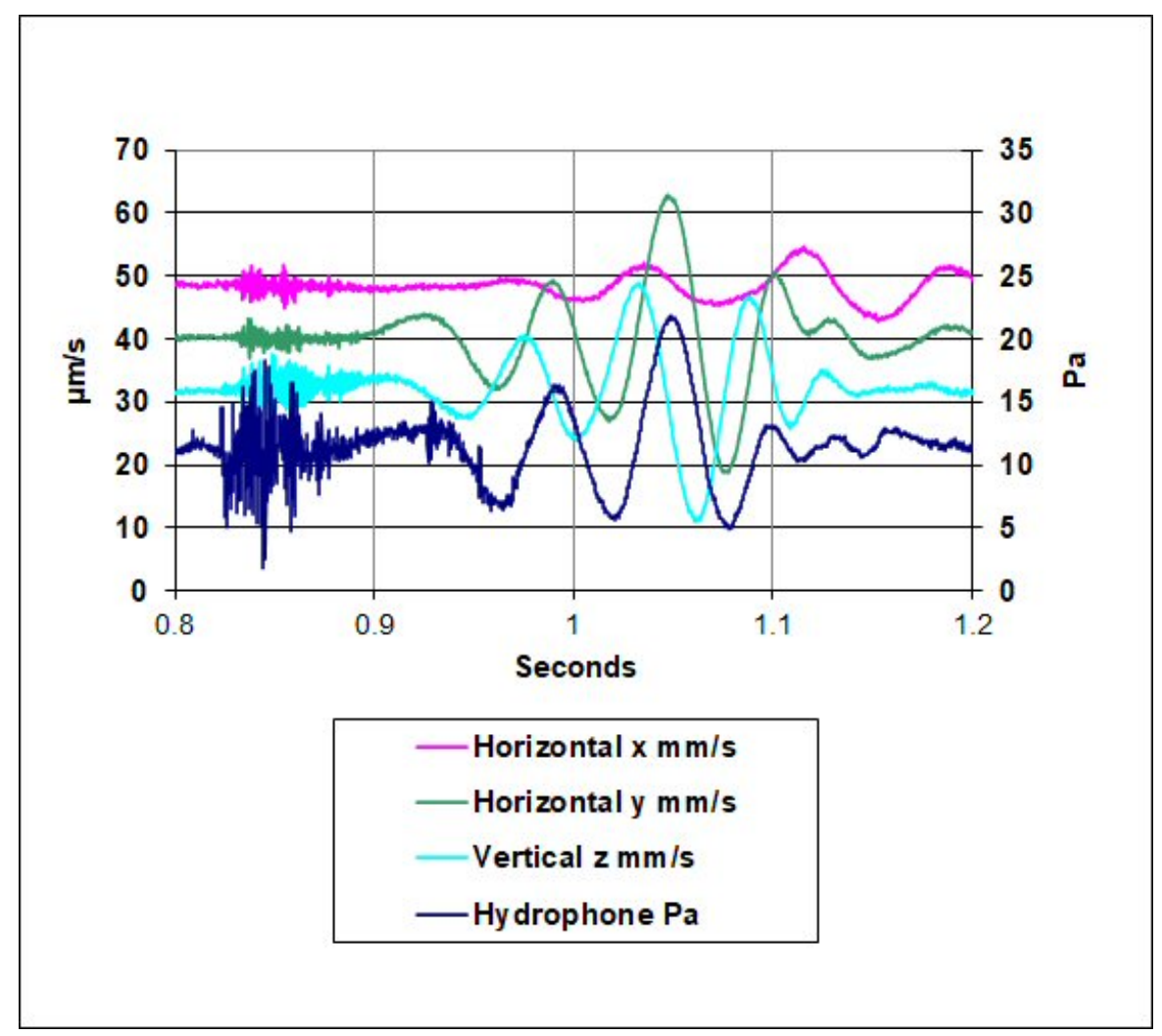

Figure 15. Test results from the trial showed three velocity components and the acoustic pressure. The right side vertical scale applies to the hydrophone pressure data, the left side to the geophone water-motion data. The plots are offset for clarity. The recorded values returned to zero after the wave had passed.

Comparing this with a typical open water impedance of $1500 \mathrm{~Pa} /(\mathrm{mm} / \mathrm{s})$ gave a VPR of 4.0, much less than the continuous wave theoretical value of 12.6 or the FE model VPR of 12.0. This was disappointing, and suggested the need to further investigate the performance of the experimental glass geophone buoy. We also recognized the risk that the heavy sledge may have affected the nearby water motion, and that we did not have details of the properties of the sediment. However, the confirmation of the wave-packet shape was encouraging.

\section{Conclusions}

The change of the forcing impulse in the FE model provided more results for higher frequencies than the previous papers. The Gaussian windowed cosine form allowed comparisons with analytic mathematical theory for continuous waves, showing similar effects, but with some changes in magnitude.

Additional analysis of the water-particle motions generated by the seismic interface waves showed a Gaussian bell-shaped time series for the water-particle kinetic energies in various modes. This was used in a fit procedure for the wave envelope to allow more precise timing to give better data for the envelope speed.

The displacement wave speed was shown to be controlled by the rate of increase with depth of the material shear wave speed. It was faster than the wave envelope speed, creating apparent movement of the displacement wave peaks through the envelope window. This explained the morphing effect reported for the pulses seen in earlier work.

The retention of energy within the most intense mode, as reported before, was confirmed by the contrast in the dispersion between the modes in the graded model, as well as that for modes generated by a layered model. Other modes were seen to have a quite 
different structure in the solid, without a change from retrograde to prograde predicted by Rayleigh [11] for the uniform half-space.

Evanescent pressure fields in the water have been analysed both by flexural plate theory and by the use of FE models, both for the graded seabed and a single-layer substrate. The water-particle motions were shown to be large by comparison to the acoustic pressures, with a large velocity pressure ratio when comparing this effect to that found in open water.

The study has also raised many questions that it is hoped can be answered by future work. More measurements and theory could help further explain the features outlined here.

Author Contributions: R.H. conceived and designed the experiments; P.M. provided support for the work. All authors have read and agreed to the published version of the manuscript.

Funding: This research received no external funding.

Acknowledgments: This work has received no external funding, but the assistance of S.P. Robinson and the staff at the National Physical Laboratory was important for the work at Wraysbury. The authors are grateful for the assistance of colleagues John King and Jim Delderfield, who helped with the figures, and many others who also provided comments on the text. Tim Swann made especially useful comments.

Conflicts of Interest: The authors declare no conflict of interest.

\section{References}

1. Thomsen, F.; Gill, A.; Kosecka, M.; Andersson, M.; Andre, M.; Degraer, S.; Folegot, T.; Gabriel, J.; Judd, A.; Neumann, T.; et al. MaRVEN-Environmental Impacts of Noise, Vibrations and Electromagnetic Emissions from Marine Renewable Energy; Final Study Report of Project RTD-KI-NA-27-738-EN-N; EUR 27738; European Commission: Brussels, Belgium, 2015.

2. Hawkins, A.D.; Johnston, C.; Popper, A.N. How to set sound exposure criteria for fishes. J. Acoust. Soc. Am. 2020, 147, 1762-1777. [CrossRef] [PubMed]

3. Popper, A.N.; Hawkins, A.D. The importance of particle motion to fishes and invertebrates. J. Acoust. Soc. Am. 2018, 143, 470-486. [CrossRef] [PubMed]

4. Madsen, P.T.; Wahlberg, M.; Tougaard, J.; Lucke, K.; Tyack, P. Wind Turbine Underwater Noise and Marine Mammals: Implications of Current Knowledge and Data Needs. Mar. Ecol. Prog. Ser. 2006, 309, 279-295. [CrossRef]

5. Halvorsen, M.B.; Casper, B.M.; Woodley, C.M.; Carlson, T.J.; Popper, A.N. Predicting and Mitigating Hydroacoustic Impacts on Fish from Pile Installations; NCHRP Research Results Digest 363, Project 25-28; National Cooperative Highway Research Program; Transportation Research Board, National Academy of Sciences: Washington, DC, USA, 2011.

6. Hawkins, A.D.; Popper, A.N. Directional hearing and sound source localization by fishes. J. Acoust. Soc. Am. 2018, 144, 3329-3350. [CrossRef] [PubMed]

7. Hamilton, E.L. Vp/Vs and Poisson's ratio in marine sediments and rocks. J. Acoust. Soc. Am. 1979, 66, 1093-1101. [CrossRef]

8. Heaney, K.; Ainslie, M.; Halvorsen, M.; Seger, K.; Müller, R.; Nijhof, M.; Lippert, T. A Parametric Analysis and Sensitivity Study of the Acoustic Propagation for Renewable Energy; US Department of the Interior Bureau of Ocean Energy Management Office of Renewal Energy Program: Stuart, FL, USA, 2020.

9. Hawkins, A.D.; Hazelwood, R.A.; Popper, A.N.; Macey, P.C. Substrate vibrations and their potential effects upon Fishes and Invertebrates. J. Acoust. Soc. Am 2021, 149, 2782. [CrossRef] [PubMed]

10. Urick, R.J. Principles of Underwater Sound, 3rd ed.; McGraw Hill: New York, NY, USA, 1983.

11. Rayleigh, L. Interface waves. Proc. Lond. Math. Soc 1887, 17, 4-11.

12. Scholte, J. On true and pseudo Rayleigh waves. Proc. K. Ned. Akad. Wet. 1949, 52, 652-653.

13. Stein, S.; Wysession, M. An introduction to Seismology Eathquakes and Earth Structure; Blackwell: Oxford, UK, 2003.

14. Shearer, P.M. Introduction to Seismology; Cambridge University Press: Cambridge, UK, 1999.

15. Achenbach, J.D. Wave Propagation in Elastic Solids; Elsevier Science Publishers: Amsterdam, The Netherlands, 1975.

16. Hazelwood, R.A.; Macey, P.C.; Robinson, S.P.; Wang, L.S. Optimal transmission of interface vibration wavelets-A simulation of seabed seismic responses. J. Mar. Sci. Eng. 2018, 6, 61. [CrossRef]

17. Godin, O.A.; Chapman, D.M. Dispersion of interface waves in sediments with power-law shear speed profiles. I. Exact and approximate analytical results. J. Acoust. Soc. Am. 2001, 110, 1890-1907. [CrossRef] [PubMed]

18. Hazelwood, R.A.; Macey, P.C. Modeling water motion near seismic waves propagating across a graded seabed, as generated by man-made impacts. J. Mar. Sci. Eng. 2016, 4, 47. [CrossRef]

19. Jensen, F.B.; Kuperman, W.A.; Porter, M.B.; Schmidt, H. Computational Ocean Acoustics; Springer Science \& Business Media: New York, NY, USA, 2011.

20. Biot, M.A. Theory of propagation of elastic waves in a fluid saturated porous solid. J. Acoust. Soc. Am. 1956, 28, 168-178. [CrossRef] 
21. Fahy, F.J. Sound and Structural Vibration; Academic Press: Cambridge, MA, USA, 1985.

22. Kinsler, L.E.; Frey, A.R.; Coppens, A.B.; Sanders, J.V. Fundamentals of Acoustics; Wiley: New York, NY, USA, 1999.

23. Institute of Sound and Vibration Research, Southampton UK, Accessed in June 2021. Available online: https:/ / www.southampton. ac.uk/engineering/research/centres/isvr.page (accessed on 1 March 2020).

24. Timoshenko, S.P.; Woinowsky-Krieger, S. Theory of Plates and Shells; McGraw-Hill: New York, NY, USA, 1959.

25. Hamilton, W.R. The Hodograph. Proc. R. Ir. Acad. 1847, 3, 344-353. 